\title{
O CUIDADO DE ENFERMAGEM FAMILIAR / EXÓTICO NA UNIDADE DE INTERNAÇÃO PSIQUIÁTRICA: DO ASILAR PARA A REABILITAÇÃO PSICOSSOCIAL ${ }^{a}$
}

\author{
The Family / Exotic Nursing Care in the Psychiatric Internment Unit: \\ From the Sheltering to the Psychosocial Rehabilitation \\ El Cuidado de Enfermería Familiar / Exótico en la Unidad de \\ Internación Psiquiátrica: Del Asilar para la Rehabilitación Psicosocial
}

Edna Gurgel Casanova

Isaura Setenta Porto

Nébia Maria Almeida de Figueiredo

\begin{abstract}
Resumo
Estudo sobre os cuidados de enfermagem psiquiátrica desenvolvidos numa unidade de internação de um hospital universitário do Rio de Janeiro. 0 objeto de estudo foi abordado com enfoque etnográfico, e os dados foram interpretados por sua aproximação ou distanciamento às bases conceituais do cuidado e aos princípios da Reforma Psiquiátrica. Neste período, algumas iniciativas desenvolvidas pela Direção do Serviço de Enfermagem contribuíram para redirecionar o olhar e agir da equipe de enfermagem. Os resultados indicam a coexistência de duas dimensões do cuidado permeadas pelas influências ambientais. A dimensão instrumental mostrou uma proeminência do modelo assistencial asilar, que se sobrepõe às transformações propostas. A dimensão expressiva indicou a valorização das singularidades dos clientes e incorporou a diversidade e o acolhimento dos profissionais mostrando a demanda mais freqüente da clientela como fundamental para a transição do modelo assistencial misto, asilar e de reabilitação, para um modelo fundamentado apenas na reabilitação psicossocial.
\end{abstract}

Palavras-chave: Cuidado de Enfermagem. Enfermagem Psiquiátrica. Saúde Mental. Reabilitação.

\begin{abstract}
Study about the psychiatric cares of nursing developed in an internment unit of a university hospital of Rio de Janeiro. The study object was boarded with ethnographic approach, and the data interpreted for its approximation or distancing to the conceptual basis of the care and to the principles of the Psychiatric Reformation. In this period, some initiatives developed by the Direction of the Service of Nursing contributed to redirect the look and to act of the nursing team. The results indicate the coexistence of two dimensions of the care permeated by the ambient influences. The instrumental dimension showed a prominence of the sheltering assistant model, which overlaps itself of the transformations proposed. The expressive dimension indicated the valuation of the singularities of the customers and incorporated the diversity and the shelter of the professionals showing the demand most frequent of the clientele as basic for the transition of the mixing assistant model, to shelter and of rehabilitation, for a model based only on the psychosocial rehabilitation.
\end{abstract}

Keywords: Nursing care. Psychiatric Nursing. Mental Health. Rehabilitation.

\begin{abstract}
Resumen
Estudio sobre los cuidados de enfermería psiquiátrica desarrollados en una unidad de internación de un hospital universitario del Rio de Janeiro. El objeto del estudio fué abordado con enfoque etnográfico, y los datos interpretados por su aproximación o distanciamiento a las bases conceptuales del cuidado y a los principios de la Reforma Psiquiátrica. En este período, algunas iniciativas desarrolladas por la Dirección del Servicio de Enfermería contribuyeron para mirar y el actuar del equipo de enfermería. Los resultados indican la coexistencia de dos dimensiones del cuidado permeadas por las influencias ambientales. La dimensión instrumental demostró una prominencia del modelo asistencial asilar, que se ha superpuesto a las transformaciones propuestas. La dimensión expresiva indicó la valuación de las singularidades de los clientes e incorporó la diversidad y el abrigo de los profesionales que demostraban la demanda más frecuente de la clientela como fundamental para la transición del modelo asistencial mixto, asilar y de rehabilitación, para un modelo fundamentado solamente en la rehabilitación psicosocial.
\end{abstract}

Palabras clave: Atención de Enfermería. Enfermería Psiquiátrica. Salud Mental. Rehabilitación. 


\section{INTRODUÇÃO}

Ao longo da nossa vida profissional temos verificado que as intervenções psiquiátricas no contexto da internação hospitalar apresentam lacunas nas atividades que buscam amenizar o sofrimento do cliente. Essa constatação reapresenta diversas questões polêmicas, dentre as quais destacamos a indicação de hospitalização integral e a função do hospital psiquiátrico. A frustração dos esforços de alguns profissionais de saúde e das expectativas dos clientes induz a refletir sobre as práticas desenvolvidas neste local.

$\mathrm{Na}$ verdade, as maneiras como a sociedade enfrenta a doença, a invalidez e o tratamento repercutem no movimento da Reforma Psiquiátrica. Por outro lado, o sucesso da iniciativa, além da consciência social e de conhecimento profissional, é também muito influenciado pela política e pela escolha das prioridades dos governos (Desviat ${ }^{1}$ ). Diante das idéias apresentadas, a vida cotidiana do hospital é uma influência decisiva no curso e prognóstico da doença mental. Assim, no contexto da internação psiquiátrica, temos questionado a compatibilidade entre o cuidado de enfermagem ofertado aos clientes e os novos dispositivos preconizados pela Reforma Psiquiátrica.

Por outro lado, ainda existe uma demanda específica das pessoas portadoras de doença mental para a internação hospitalar em regime integral, que devem receber cuidados afastados dos princípios e pressupostos e das práticas derivadas do modelo assistencial asilar/manicomial. Independente dos locais de assistência psiquiátrica, torna-se necessária uma reflexão sobre a prática clínica, incluindo o cuidado de enfermagem, para a superação da filosofia da assistência fundamentada neste modelo.

Considerando a problemática apresentada e com o propósito de melhor orientar o estudo, as seguintes questões norteadoras foram elaboradas: (a) Como os cuidados de enfermagem são realizados no cotidiano de uma unidade de internação psiquiátrica, em face das mudanças derivadas da reabilitação psicossocial oriunda da Reforma Psiquiátrica? (b) Como as modificações introduzidas na dinâmica e no cotidiano da unidade de internação psiquiátrica influenciam na realização dos cuidados de enfermagem?

$\mathrm{Na}$ presente investigação, o objeto de estudo abarca os cuidados desenvolvidos pelos integrantes da equipe de enfermagem de uma unidade de internação de hospital universitário psiquiátrico pertencente à universidade pública sediada no Rio de Janeiro. Os inúmeros desafios dessa empreitada são complexos e, apesar da existência de experiências inovadoras em desenvolvimento em diferentes ambientes, ainda são poucos os estudos sobre 0 cuidado de enfermagem psiquiátrica no contexto da Reforma Psiquiátrica.

0 momento atual é de redefinições no campo da assistência à clientela, na área da saúde mental. Nesse sentido, a Enfermagem também vem desenvolvendo atividades e experiências. Mas, para subsidiar a continuidade dessas iniciativas com maior visibilidade, torna-se necessária uma leitura crítica das atividades e aplicações do saber da Enfermagem na área da saúde mental, no cotidiano do hospital psiquiátrico. Uma das maneiras de ler criticamente a realidade assistencial é o desenvolvimento de investigações, como é o caso deste texto. Assim, considerando-se este contexto, foram elaborados os seguintes objetivos de pesquisa:

(a) Descrever os cuidados de enfermagem realizados no cotidiano da prática da equipe de enfermagem de uma unidade de internação psiquiátrica;

(b) Analisar os cuidados de enfermagem desenvolvidos na unidade de internação psiquiátrica e suas implicações, à luz do processo de reabilitação psicossocial.

\section{METODOLOGIA}

A opção pela abordagem qualitativa nesta pesquisa decorreu da própria natureza do objeto da investigação, pois o cuidado em enfermagem psiquiátrica é impregnado de diversas influências, quais sejam: (a) vínculos dialéticos, que incluem aspectos da ordem dos valores, da cultura e da ideologia de nossa sociedade; (b) determinantes sócio-econômicos, culturais e políticos imbricados nas situações de cuidado em enfermagem; e (c) subjetividade de profissionais e clientes, que aparece de maneira implícita ou explícita, neste objeto de investigação.

Além disto, a natureza imprecisa do objeto da Psiquiatria configura-se como um grande desafio para as pesquisas desenvolvidas nesta área, considerandose que ele abrange o homem na sua experiência de sofrimento mental aliado à necessidade de compreender valores, crenças e motivações imersos no seu próprio contexto de significados. Confirmando a opção realizada, Najmanovich², ao analisar a dominância do método quantitativo, em relação ao qualitativo, assinala que ficam fora dele a emoção e a beleza, a ética e a estética, a cor e a dor, o espírito e a fé, a arte e a filosofia, o corpo emocional e o mundo subjetivo.

Diante da necessidade de apreender as práticas de cuidados no cotidiano da Enfermagem junto a 
clientes psiquiátricos internados, adotamos uma abordagem aproximada à etnografia. A etnografia é empregada para designar os resultados empíricos e descritivos da ciência do homem, visualizados no contexto em que ele atua e vive (Malinowski ${ }^{3}$ ).

Neste sentido, o cotidiano da equipe de enfermagem em situações de cuidado foi observado para desvelar suas rotinas e dinâmicas. Em geral, 0 elemento relacional implícito no cuidado de enfermagem abre possibilidades para se obter uma visão do conjunto sobre as práticas exercidas pelos integrantes da equipe de enfermagem. É difícil separar o cuidado do processo de trabalho de enfermagem, e a neutralidade científica é uma condição dificilmente alcançável. Assim, procuramos manter um distanciamento crítico e não ingênuo, para atingir o rigor científico esperado em qualquer pesquisa.

Esse foi um esforço imprescindível, pois o campo da pesquisa era próximo aos pesquisadores, uma vantagem em termos de acesso às pessoas e aos dados e informações do cotidiano. Mas, por outro lado, exigia, em outros momentos, um grau de distanciamento em relação às situações observadas. A proximidade e o distanciamento foram exercitados no próprio trabalho de campo da pesquisa. Silva ${ }^{6}$ confirma nossa opção ao dizer que a familiaridade representa algumas facilidades, como o conhecimento dos códigos de comportamentos do grupo. Por outro lado, é necessário redobrar atenção, para não limitar a pesquisa aos aspectos e posições contingenciais.

As sugestões de Velho e Da Matta ${ }^{5}$ sobre a transformação do exótico em familiar e do familiar em exótico e o distanciamento social e psicológico influenciaram também a orientação deste trabalho. Assim, num primeiro momento foi necessário que estranhássemos o que era supostamente conhecido (cuidado de enfermagem psiquiátrica). Para orientar a observação deste cuidado (olhar, ouvir e escrever) elaboramos as seguintes perguntas: (a) Como o cuidado apresenta-se na unidade de internação psiquiátrica? (b) Ele é conhecido?

Assim, o cuidado de enfermagem familiar é aquele orientado pelo modelo normativo do sujeito, que tem como horizonte a cura (normalidade). Ele é 0 ato de cuidar orientado pelo paradigma biomédico, com a finalidade de devolver o cliente à normalidade recorrendo-se preferencialmente ao diagnóstico médico, para seu planejamento e desenvolvimento. Esse cuidado é marcado pelo processo histórico, marcado pelas dimensões instrumental e técnicoadministrativa. Suas características mostram-se pela presença de cuidados rotineiros e "mecanicamente" realizados, que apresentam o risco de incorporar 0 (pré)conceito e o (des)valor relativos ao cliente, em sua autonomia e singularidade.

Por outro lado, o cuidado exótico aponta para uma prática capaz de criar novos dispositivos que ajudem o sujeito a ordenar suas dimensões psíquicas e suas práticas sociais, de maneira mais criativa. Ele consiste na ação terapêutica de cuidar, alicerçada em diversas áreas do conhecimento, com o objetivo de contribuir para a reabilitação psicossocial. Por conseqüência, ele opera considerando-se as multicausas do adoecimento psíquico abandonando, assim, o saber centrado no diagnóstico médico.

Então, multicuidados surgem como cuidados exóticos, tais como baile e assembléia de clientes, residência terapêutica, salão de beleza, oficina terapêutica "Saúde e Sexualidade" e visita domiciliar, pois esses são dispositivos terapêuticos que desenvolvem o cuidado com orientação, objetivos e estruturas diferenciados daqueles cuidados considerados como familiares.

Adotamos esta classificação de cuidado familiar ou cuidado exótico de maneira flexível. Um tipo de cuidado considerado como familiar (administração de medicamentos), pode ser transformado em cuidado exótico, quando existe uma monitorização dos sintomas através da terapêutica medicamentosa vinculada aos aspectos da qualidade de vida dos clientes e ao resgate a sua capacidade para a vida social. Então, a ação de administrar o medicamento adquire um novo sentido transformando-se em cuidado exótico.

Procuramos observar e registrar também o "nãodito", as peculiaridades sutis, muitas captadas nas entrelinhas dos discursos e em outras manifestações não-verbais. 0 acesso a esse tipo de dados é considerado acesso aos imponderáveis da vida real (Malinowski ${ }^{3}$ ). Entre eles destacam-se a maneira, o gesto, o tom da voz ao abordar o cliente, a disponibilidade interna dos integrantes da equipe de enfermagem e seu respeito ao realizar o cuidado com o cliente. Esses imponderáveis são essenciais ao trabalho de campo, pois mostram "o não-dito", as pequenas ações e intenções, as escolhas pelos tipos de cuidados e as prioridades estabelecidas no cotidiano do cuidado de enfermagem.

Escolhemos o estudo de caso para tipificar a pesquisa, pois ele permite estudar o fenômeno em sua singularidade, com possibilidade de aprofundamento $\left(\right.$ Becker $\left.^{7}\right)$. 0 cenário da pesquisa foi uma unidade de internação em regime integral do Instituto de Psiquiatria da Universidade Federal do Rio de Janeiro (IPUB). Nesse hospital, reconhecido como referência em Saúde Mental pela Organização Mundial de Saúde, 
desenvolvem-se atividades de ensino, pesquisa, extensão e assistência.

Participaram do estudo sete enfermeiros e dezessete profissionais de enfermagem de nível médio, que trabalhavam na unidade de internação denominada Enfermaria $2^{b}$. Nela, os integrantes da equipe prestam cuidados junto a setenta e dois clientes distribuídos em quartos coletivos, acrescidos de quatro clientes também portadores de intercorrências clínicas, cujos leitos estão situados em local contíguo ao posto de enfermagem.

Desde 1994, vem sendo realizadas mudanças e reformulações nos cuidados aos clientes psiquiátricos. Naquele período, a Professora Cristina Maria Douat Loyola assumiu a Diretoria de Enfermagem implementando mudanças na filosofia do cuidado, para adequá-lo à Reforma Psiquiátrica (Loyola Miranda ${ }^{11-19}$ ). Assim, a mudança iniciou-se de uma prática pautada no cuidado familiar, para uma revisão dessa prática em direção do cuidado exótico.

Solicitamos autorização para realizar a pesquisa com instrumento padronizado encaminhado à Direção do IPUB. E foram encaminhados ao Comitê de Ética em Pesquisa cópia do projeto de pesquisa, cópia do curriculum vitae da pesquisadora responsável pela coleta de dados e termo de consentimento livre e esclarecido, em atendimento à Resolução n0196 / 96 do Conselho Nacional de Saúde do Ministério da Saúde $\left(\right.$ Brasil $\left.{ }^{8}\right)$. 0 Comitê aprovou a realização da investigação na Enfermaria 2 da Instituição.

0 método principal para a coleta de coleta de dados foi a observação participante associada às técnicas de entrevista livre e análise documental. A coleta propriamente dita foi realizada em 2001, com um total de noventa horas de observação de campo e a realização de dez entrevistas vinculadas às situações de cuidado observadas e significativas para a análise do cuidado de enfermagem. As falas dos participantes foram gravadas após a exposição prévia da pesquisa e a obtenção de suas assinaturas no termo de consentimento livre e esclarecido.

0 tratamento dos dados foi realizado a partir da técnica de análise de conteúdo $\left(\operatorname{Bardin}^{9}\right)$. Para a definição das categorias utilizamos o modelo aberto, no qual as categorias formam-se no curso da própria análise (Laville e Dionne ${ }^{10}$ ). Os temas encontrados apontaram para as seguintes categorias empíricas: (a) Ambiente do Cuidado de Enfermagem e o Cuidado com o Ambiente e o Cliente: de uma Psiquiatria fechada para uma aberta - descerrando as portas; (b) Cuidado a partir de avaliação prévia da Enfermagem: a manutenção de uma prática; e (c) Cuidado por solicitação do cliente: a transição do cuidado de enfermagem psiquiátrica. $\mathrm{Na}$ análise e interpretação dos resultados, as categorias empíricas construídas foram confrontadas com o conteúdo e princípios da Reforma Psiquiátrica e da literatura da Enfermagem sobre o cuidado e de Enfermagem Psiquiátrica, que se apresentava em consonância com essa Reforma.

\section{ANÁLISE E INTERPRETAÇÃO DOS RESULTADOS}

A análise e interpretação dos resultados relativos a cada uma das categorias construídas estão apresentadas a seguir.

\section{Categoria 1 \\ Ambiente do cuidado de enfermagem e o cuidado com o ambiente e cliente: De uma hospitalização fechada para uma aberta - descerrando as portas}

Um serviço psiquiátrico de qualidade apresenta um campo de possibilidades que se reorganizam cotidianamente, tendo em vista a garantia da reabilitação dos clientes, nos seus limites e potencialidades individuais. A presença do hospital psiquiátrico não implica a obrigatoriedade de modelo manicomial. Assim, conseqüentemente, a existência da unidade de internação hospitalar; localizada no hospital, não implica sua filiação ao modelo manicomial.

A partir da Reforma Psiquiátrica, implementaramse vários dispositivos de atenção e mudanças no processo de cuidados aos clientes. Em alguns casos, ainda mesmo com os novos espaços de atendimento, encontram-se práticas rotinizadas e estereotipadas, abandonos, maus-tratos e desesperança. Em geral, dentre outras justificativas, são feitas reformas nas instalações hospitalares, para melhorar sua classificação junto aos órgãos financiadores, com a finalidade de o hospital ser mais bem remunerado pelos serviços prestados. Essas reformas buscam caracterizálo como instituição inserida no movimento de reorganização da assistência psiquiátrica, cuja iniciativa é uma estratégia denominada como adesão cosmética $\left(\right.$ Bezerra $\left.^{12}\right)$. Em contraposição, o processo de reabilitação pode operar em qualquer lugar, seja numa enfermaria, residência terapêutica ou residência comum.

Para isto, esses espaços devem ser transformados em lugares, um movimento do estar para o habitar $\left(\right.$ Saraceno $\left.{ }^{20}\right)$. Neste sentido, o cuidado em enfermagem psiquiátrica, denominado exótico, por estar voltado para a reabilitação, exige, além da utilização de vários saberes, o reconhecimento fundamental acerca dos investimentos físico-estruturais. Então, a transformação de uma enfermaria num espaço terapêutico, do ponto de vista físico e operativo, é função de todos os que cuidam e interagem com o cliente internado. 
Em relação ao exposto, a descrição etnográfica poderia proporcionar uma idéia do ambiente espacial do IPUB (racional), que une os corpos e mentes que ali (con)vivem. Entre outros resultados, verificou-se nos espaços recentemente conquistados pela Enfermagem e seus clientes um reflexo da transição da arte de cuidar, ao mesmo tempo em que sua expansão foi ampliada. Foi possível perceber, também, que nem tudo é harmônico e linear em termos de estrutura física, pois o espaço foi organizado para acolher os corpos em sofrimento mental. A cartografia do IPUB mantém a idéia original do tempo de sua construção de que a loucura deveria ser guardada, uma compreensão atualmente marcada por rupturas.

Uma dessas rupturas é a abertura das portas, que libertou os clientes através dos novos contratos sociais. Desta maneira, criou-se uma nova configuração territorial, em cima de um ambiente histórico, no qual se busca consonância com as diretrizes da Reforma Psiquiátrica e as necessidades e direitos desses clientes. A enfermeira Silvia e a auxiliar de enfermagem Daisy ressaltaram as vantagens em relação à reorganização das enfermarias e abertura das portas, afirmando que:

Percebo que o doente da Enfermaria 2, por estar com a porta aberta, se comporta de maneira diferente. Ele está menos ansioso para sair, porque ... sabe que amanhã vai sair às nove horas. 0 doente da Enfermaria 2, conforme disse um cliente, lá ele se sente menos internado. Ele acha que, com a porta aberta, ... não está tão doido assim (Enf. ${ }^{2}$ Silvia).

Durante o dia, com esse livre acesso ao pátio externo, os clientes da Enfermaria 2 têm acesso às diversas oficinas e contato com pessoas menos adoecidas que vem visitar, representante de laboratórios, pessoal da enfermaria, é um ponto positivo da enfermaria aberta. Assim, diminuiu o número de ocorrências, não que eles fiquem mais dispersos, mas devido a outros convívios. Quando você abre a porta, muitas coisas mudam (aux. de Enf. ${ }^{a}$ Daisy).

Para o bem-estar do cliente e tentando suprir as deficiências institucionais, os integrantes da equipe de enfermagem hoje, como no passado, desdobram-se para preencher as lacunas. Por outro lado, também é plausível considerar esse comportamento como um recurso para preencher o espaço vazio, decorrente da indefinição na prática da Enfermagem Psiquiátrica pelo momento de transição para um novo modelo de cuidado orientado para reabilitação psicossocial dos clientes.
Esse posicionamento tornou-se particularmente compreensível naquelas situações em que os integrantes da equipe desenvolviam ações subsidiárias, historicamente determinadas e características do modelo asilar/manicomial, tais como a vigilância sobre 0 ir-e-vir dos clientes (porta da enfermaria - chaves) e 0 atendimento do telefone.

Ao refletir sobre o ambiente do cuidado destacamse algumas tendências do ambiente que influenciam 0 cuidado entendido como familiar e exótico (Velho ${ }^{4}$ e Da Matta $\left.{ }^{5}\right) .0$ ambiente observado, no qual acontece 0 cuidado, significa algo além de simples comodidade e estética, numa instituição considerada dispositivo social. A hospitalização provoca um abandono do espaço do cliente em sua residência, geralmente compulsório, e de seus rituais e simbolismos, para imergir muitas vezes, em outros espaços desconhecidos, como afirma Collière ${ }^{21}$.

Assim, apesar das modificações ambientais, que atendem parcialmente aos princípios da Reforma Psiquiátrica, elas ainda são incapazes de influenciar significativamente no cotidiano do cuidado de enfermagem. A constatação desta afirmativa envolve 0 trabalho na dimensão expressiva, que é dependente da singularidade de cada profissional. E assim, esse trabalho tem encontrado dificuldade para ser incorporado ao cotidiano assistencial de enfermagem, pois depende de outros aspectos vinculados a quem cuida.

Somente tornou-se possível aos integrantes da equipe de enfermagem exteriorizarem as dimensões expressivas do cuidado quando foi desenvolvido um processo de reflexão e amadurecimento profissionais, através da criação de espaços nos quais podiam debater e se preparar, como por exemplo, o grupo de supervisão de enfermagem, o grupo de reflexão com os auxiliares de enfermagem e as sessões clínicas. Esses espaços também possibilitam a compreensão das influências ambientais no cuidado de enfermagem psiquiátrica.

\section{Categoria 2}

\section{Cuidado a partir da avaliação prévia da Enfermagem: A manutenção de uma prática de cuidados de enfermagem psiquiátrica}

Esta categoria foi construída a partir da identificação das necessidades de cuidados e da participação dos integrantes da equipe de enfermagem em atividades inovadoras e de interesse dos clientes, segundo a perspectiva da Reforma Psiquiátrica. A dimensão instrumental do cuidado esteve presente em todas as situações de cuidado, e sua prática esteve atrelada predominantemente ao modelo biomédico. Assim organizada, a Enfermagem ainda aparece como coadjuvante do tratamento médico. Conseqüentemente, 
limita-se a possibilidade do cuidado de enfermagem, enquanto ato criador e original.

Neste sentido, a baixa participação dos integrantes da equipe de enfermagem nos recentes dispositivos terapêuticos desenvolvidos na Instituição, tais como 0 baile, o salão de beleza, a assembléia de pacientes e o acompanhamento ao pátio, reforçam o modelo assistencial que recorre à medicação como principal dispositivo terapêutico. A manifestação transcrita a seguir é elucidativa desta afirmação:

O salão não tinha sido planejado desta maneira. Isto é, todos deveriam também trabalhar no salão. No entanto, todos [somente] encaminham os clientes, inclusive eu (Enfa . Carolina).

Apesar de ressaltarem a finalidade terapêutica desses novos dispositivos de cuidado, a resistência em participar das iniciativas parece decorrer de um conflito entre a cristalização das formas de cuidado e/ou da instabilidade provocada pela multiplicidade de aspectos e demandas implícitas e explícitas na proposta de reestruturação da assistência psiquiátrica.

Desta forma, nem o cliente nem os integrantes da equipe de enfermagem são considerados elementos valiosos do processo terapêutico. Segundo Corbisier ${ }^{22}$, nesse modelo geralmente quem trabalha basicamente é o medicamento. A posição de Lopes $^{23}$ ressalta que a ação de cuidar é construída no cotidiano das atividades de enfermagem. Assim, alguns integrantes da equipe compreendiam a necessidade de envolvimento no processo terapêutico reconhecendo sua participação em contraposição ao que havia sido planejado. Mas, a influência do modelo asilar ainda é forte, o que os fez constatar que participavam do processo terapêutico, apenas de maneira mínima.

Os dados expõem que os integrantes da equipe ainda permaneciam fortemente marcados pelas influências próprias do modelo asilar, apesar de ele ser altamente criticado pelos próprios envolvidos. Em compensação, o traço menos visível dos integrantes foi a dimensão expressiva e seus valores imateriais, como a afetividade, a empatia e iniciativa, pouco presentes na ação singular do cuidado de enfermagem.

Esta análise confirma-se a partir de um trecho do diário de campo: o horário da manhã geralmente era sempre considerado muito agitado. Todos os integrantes da equipe de enfermagem tinham sua atenção dirigida para os tratamentos biológicos e as ações voltadas para o confor to e higiene dos corpos dos clientes. Desta maneira, nenhum integrante da equipe esteve sentado no pátio interno para conversar com os clientes. Da mesma forma, ninguém estava olhando/supervisionando ou interagindo com os clientes no pátio externo (registro de 16/04/2001).

$\mathrm{Na}$ organização dos cuidados de enfermagem, as necessidades do cliente e as possibilidades de ele exercer sua autonomia foram pouco consideradas. Assim, o sujeito do cuidado, o cliente com sua diferença, maneira de ser e suas possibilidades, foi pouco privilegiado pelos integrantes da equipe de enfermagem. Por isso, às vezes eles agiam como reprodutores de um cuidado institucionalizado, cujos alicerces encontravam-se basicamente no antigo modelo asilar/manicomial ainda presente.

A relação de cuidado foi acompanhada de troca entre os integrantes da equipe de enfermagem e os clientes, como Silva ${ }^{24}$ enfatiza, e a reabilitação psicossocial envolvia a modificação de um desvalor natural atribuído ao cliente psiquiátrico em um valor possível. Assim, essa relação parecia estar começando a mostrar a construção de um cuidado que considerava a cidadania e os novos contratos de vida (trabalho, lazer, moradia) para os clientes.

Em reforço a esta mudança de comportamento dos integrantes da equipe, outro trecho do diário de campo com cuidados familiares aparentes destacou sua transformação em cuidados exóticos: todos os procedimentos técnicos (verificação de sinais vitais, auxílio na alimentação, higiene, e outros) foram feitos de maneira delicada, quase sempre atendidos os desejos dos clientes (registro de 13/04/2001).

Diante dos resultados apontados nesta categoria, verificamos que a dimensão instrumental do cuidado se apresentava mais significativa, ao ser comparada à dimensão expressiva. Assim, nesta unidade de internação psiquiátrica, que apresentava a transição do modelo asilar para um modelo de reabilitação psicossocial, os profissionais da equipe de enfermagem viabilizavam as ações de cuidados majoritariamente numa dimensão instrumental.

No entanto, existiram pistas relacionadas ao cuidado exótico, apesar do pequeno desenvolvimento, que mostravam a dimensão expressiva dos integrantes da equipe de enfermagem na realização de cuidados, quando demandavam a utilização de si mesmos de maneira terapêutica. Eles geralmente aconteceram no interior dos dispositivos terapêuticos (salão de beleza, assembléia, baile e pátio) e, eventualmente, durante as atividades cotidianas na enfermaria. Dessa maneira, alguns integrantes da equipe de enfermagem já haviam incorporado o atendimento das necessidades existenciais dos clientes sob seus cuidados. Quanto à relação entre integrantes da equipe e clientes, em determinados momentos, os cuidados de enfermagem estimulavam a autonomia do cliente; em outros 
momentos, eles eram norteados pela ideologia representativa $\mathrm{da}$ ordem institucionalizada $\mathrm{e}$ hierarquizada, característica do cuidado familiar/asilar.

$\mathrm{Na}$ abordagem das maneiras pelas quais aconteciam os cuidados a partir da avaliação prévia da enfermagem, os profissionais demonstraram que a função social do cuidado era pouco percebida e considerada, como determinante da reabilitação psicossocial do cliente. As tecnologias de cuidados utilizadas, em sua maioria, apoiavam-se na perspectiva organicista da doença mental. Dessa forma, a natureza dos cuidados estava mais fortemente orientada para o plano da racionalidade, caracterizados como cuidados familiares/ instrumentais, do que para a estética/subjetividade, características do cuidado exótico/expressivo.

\section{Categoria 3 \\ Cuidado por Solicitação do Cliente: A transição da prática do cuidado de enfermagem psiquiátrica}

Nesta categoria foram analisados os cuidados de enfermagem, com ênfase nas necessidades dos clientes. Ao delimitar esse foco de reflexão, destacase que, na constituição do saber médico como discurso científico e na hegemonia do modelo anátomofisiopatológico, ganharam centralidade os saberes que recaem sobre o corpo biológico. Esta posição obteve confirmação quando foi identificada a tendência de predomínio da dimensão biológica no processo de construção de conhecimentos psiquiátricos.

Para identificar os cuidados de enfermagem em consonância com o novo modelo de atenção psiquiátrica, registrou-se a intervenção de uma enfermeira considerada um cuidado compatível com a perspectiva da autonomia. Para ilustrar, um trecho do diário de campo destacou uma situação de uma cliente muito idosa, que permanecia acamada durante a maior parte do tempo. Ela ouviu a chamada para o lanche e começou a gritar pedindo comida. De dentro do posto, a enfermeira disse a ela: Vai lá C.! A cliente levantou-se e foi ao refeitório, fazendo, depois, uma parada no pátio. Uma auxiliar de enfermagem aproximou-se dela carinhosamente, entregando-lhe uma bandeja com o lanche, que estava sendo distribuído (registro de 30/4/2001).

Este gesto, passível de caracterização como cuidado exótico, faz parte de inúmeros comportamentos observados no cotidiano dos integrantes da equipe de enfermagem. Porém, são pouco valorizados e reconhecidos pelos próprios profissionais como cuidados de enfermagem. Apesar disso, a ação da enfermeira, corroborada pelo gesto da auxiliar de enfermagem, propiciou uma interação estimulante à autonomia da cliente.

No espaço do hospital psiquiátrico, no qual coexistem pacientes com diversas necessidades psicológicas e sociais, o cuidar em enfermagem psiquiátrica deve ter por finalidade uma prática clínica individualizada, que pressupõe um cuidado ético. Quaisquer que sejam as características operacionais do hospital, é imprescindível que a dignidade e humanidade dos que estão sob nossos cuidados sejam consideradas.

Preservar a dignidade e humanidade dos clientes durante a realização dos cuidados implica a atenção, destacando-se, particularmente, a fala do cliente representativa de seus desejos e de suas condições existenciais e relações com as pessoas e o mundo. As palavras da enfermeira Priscilla ressaltam o estatuto positivo que ela atribui à fala do paciente:

(...) Fui depois conversar com o paciente que levantou a situação do roubo na Assembléia dos pacientes. Ele mesmo, juntamente com outros pacientes, estimulados por mim, chegaram a conclusão de que a Assembléia não é espaço para um ficar "dedurando" o outro. Nestas situações, tento envolver ao máximo os pacientes para que, juntos, consigamos resolver as situações, sempre baseados no diálogo (...) (Enf. Priscilla).

Neste depoimento, a escuta diferenciada da fala dos pacientes aponta para uma nova visão do doente mental, que busca garantir sua participação no processo terapêutico. Assim, é possível utilizar uma tecnologia de cuidado, que considera a prática como uma instância terapêutica, que envolve os indivíduos no movimento permanente de produção da instituição $\left(\right.$ Goldberg $\left.{ }^{25}\right)$. A postura desta enfermeira exemplifica uma abordagem característica do cuidado exótico.

Apesar de algumas ações de enfermagem terem sido identificadas como cuidado exótico, ficou patente que a maioria dos sujeitos do estudo ainda estava impregnada por práticas cristalizadas do modelo asilar, nas quais a singularidade do cliente era pouco considerada. Nessa linha operacional e para preencher a falta do diálogo, da escuta e das práticas reabilitadoras, freqüentemente os profissionais recorreram à terapia medicamentosa.

0 comportamento dos profissionais, descrito num trecho do diário de campo, expressou a maneira pela qual os integrantes da equipe de enfermagem ainda privilegiavam a psicofarmacoterapia como uma das bases para o cuidado: o cliente $\mathrm{H}$. pede a uma médica que estava no posto de enfermagem para prescrever dois comprimidos de diazepan ${ }^{\circledR}$, porque "a cliente $C$. 
me deixa nervoso". A enfermeira e a médica concordaram dizendo que receberia apenas um comprimido. A médica prescreveu em seguida. Um auxiliar preparou a medicação e a administrou para 0 cliente, sem nenhum diálogo (registro de 30/4/2001).

Por outro lado, um posicionamento crítico, mas sutil, em relação à medicação vem sendo freqüente no grupo pesquisado, embora reconhecessem a farmacoterapia como um dos tratamentos significativos. Assim, os integrantes da equipe de enfermagem tendiam a reordenar seu trabalho na direção do cuidado exótico. As falas a seguir mostraram essa tendência:

Só medicar não adianta. Primeiro você medica, depois conversa. No começo [na crise], ele precisa muito de remédio. Com a conversa, você pode até tirar a medicação (Auxiliar de enfermagem Tatiana).

(...) Às vezes, o paciente entra em pânico. Tem que conversar com ele. Está muito viciado em medicação, e sabe a hora que pode tomar. No meu plantão, dizia que só podia tomar SOS a partir da meia-noite. Então, eles vinham exatamente nessa hora, cobrar a medicação (Enfermeira Camilla).

Boff ${ }^{26}$ afirma que uma ética nova pressupõe uma ótica nova. 0 movimento de reorganização psiquiátrica está permitindo uma nova visão sobre aqueles que têm um modo distinto de ser na vida. Conseqüentemente, existiram os integrantes da equipe de enfermagem usando mecanismos repressivos, para legitimar a ordem estabelecida (cuidado familiar) instrumental). Outras profissionais romperam com esta ordem buscando novas maneiras para desenvolver o cuidado de enfermagem psiquiátrica (cuidado exóticol expressivo). Existiam vários caminhos para alcançar essas novas maneiras, que estavam sendo construídos com a participação de todos, através de pequenas/ grandes atitudes no cotidiano do serviço.

Um outro aspecto a ser destacado refere-se à integralidade do cuidado, como parte da existência humana. É fundamental olhar para a totalidade existencial do cliente. No entanto, o cuidar, enquanto uma atividade interacional, ainda se conjuga em diferentes ritmos. Importa buscar respostas para esse descompasso entre os cuidados de âmbitos biológico e psicológico da clientela.

0 que chama atenção é a dificuldade, quer no hospital psiquiátrico, quer no hospital geral, para 0 desenvolvimento de um cuidado orientado para uma relação sujeito-sujeito $\left(\right.$ Boff $\left.^{19}\right)$ e reconhecido como característico da dimensão presente no cuidado familiar.
Assim, a dimensão expressiva do cuidado de enfermagem ganhou centralidade na relação sujeito-sujeito.

As expectativas dos clientes vinham ao encontro dos princípios que estão reorientando a Reforma Psiquiátrica. Mas, como em qualquer processo de mudança encontraram-se resistências e perplexidades no grupo estudado, que estavam sendo superadas, a partir de atitudes criativas e solidárias. Essa superação fundamentava-se em atitudes baseadas tanto nos princípios relativos a um cuidado mais integral como nos pressupostos da reabilitação psicossocial.

Assim, sem retrocessos na orientação terapêutica da Instituição, e à medida que os integrantes da equipe de enfermagem superem as dificuldades cotidianas ao cuidar do cliente com uma nova ótica, as novas formas de entendimento do trabalho serão fortalecidas dando origem a uma prática diferenciada de enfermagem, mais disseminada e uniforme entre os profissionais de enfermagem.

Os resultados analisados nesta categoria mostram as realidades vivenciadas tanto pelos integrantes da equipe de enfermagem como pelos clientes, que foram modificadas sob a égide de novos contratos regidos pela mudança paradigmática da Psiquiatria. Assim, os cuidados solicitados pelos clientes inseriram-se tanto na dimensão instrumental como na dimensão expressiva.

\section{CONSIDERAÇÕES FINAIS}

Ao decidir estudar o cuidado de enfermagem em uma unidade de internação psiquiátrica, tínhamos a convicção de que estávamos diante de um fenômeno profundamente dinâmico. Essa pré-noção confirmouse durante a coleta de dados, especialmente ao identificar encontros e desencontros entre os integrantes da equipe de enfermagem com os clientes, no cotidiano profissional. Essa configuração de dinamismo revela-se também porque, ao mesmo tempo em que o cuidado demanda atitude de acolhimento (mas não de submissão), requer um saber-fazer novo, criativo e suficientemente estimulador de uma autonomia, que capacite o cliente para a reconstrução de seu projeto de vida e sua história.

Sob o ângulo epistemológico, durante todo o estudo, tivemos clareza sobre a carga de subjetividade que permeia as pesquisas qualitativas com abordagem antropológica, no campo dos cuidados de enfermagem em saúde mental. Cumpre ressaltar que a abordagem inspirada na etnografia foi muito valiosa, no sentido de propiciar um olhar abrangente e, ao mesmo tempo, voltado para pontos especíicos, em função dos objetivos da pesquisa.

Utilizando os conceitos de familiar e exótico emprestados da Antropologia, analisamos os cuidados 
de enfermagem desenvolvidos na enfermaria, procurando interconectar o sistema microssocial do IPUB com os cuidados de enfermagem, códigos culturais e comportamentos singulares dos clientes. Assim, buscamos mergulhar no cuidado de enfermagem que, num momento de transição, evidencia um dinamismo daqueles que pretendem passar de um espaço asilar para o da reabilitação psicossocial.

Na primeira categoria, focalizamos a dimensão espacial (ambiente) da enfermaria e sua influência no cotidiano dos cuidados de enfermagem. Foi possível perceber então, que alguns espaços refletem a transição para lugares mostrando uma mudança na arte de cuidar de um modelo asilar para um de reabilitação psicossocial.

A análise das relações entre o conteúdo das narrativas e da descrição etnográfica levou-nos à segunda categoria. Ela foi construída a partir da identificação das necessidades de cuidados para os clientes, segundo a ótica dos integrantes da equipe de enfermagem. Nela, a dimensão instrumental do cuidado esteve presente em quase todas as situações apresentadas. Essa dimensão, historicamente determinada pelo modelo de assistência asilar/ manicomial, até hoje exerce influências marcantes no comportamento dos profissionais de enfermagem.

A terceira e última categoria emergiu a partir de dados relativos ao atendimento das solicitações dos clientes. Nela verificamos uma tendência à transição da prática de enfermagem do corpo receptor do cliente, enquanto objeto do cuidado (familiar), para o corpo solicitador do cliente, enquanto sujeito do cuidado (exótico).

Diante destes resultados pode ser pertinente afirmar que o cuidado de enfermagem prestado aos clientes psiquiátricos internados no IPUB encontra-se numa fase de transição para concretizar as mudanças necessárias às transformações do modelo assistencial em psiquiatria, de um enfoque asilar para uma abordagem de reabilitação psicossocial.

Nesse sentido, a presente pesquisa, ao problematizar o cotidiano do cuidado de enfermagem psiquiátrica em unidade de internação hospitalar reatualiza a idéia de que é necessário e saudável um questionamento diário sobre os serviços de enfermagem e sobre o cuidar neles desenvolvidos. 0 entendimento sobre o cuidado exótico acontece a partir da construção de novos caminhos realimentando aqueles que cuidam/ajudam na diminuição do sofrimento dos clientes.

\section{Referências}

1. Desviat M. A reforma psiquiátrica. Tradução de Vera Ribeiro. Rio de Janeiro (RJ): FIOCRUZ; 1999

2. Najmanovich D. 0 sujeito encarnado-questões para pesquisa no/ do cotidiano. Rio de Janeiro (RJ): DP\&A; 2001.

3. Malinowski B. Objetivo, método e alcance desta pesquisa. In: Guimarães AZ, organizadora. Desvendando máscaras sociais. Rio de Janeiro (RJ): Zahar; 1975.

4. Velho G. Observando o familiar. In: Nunes 0, organizador. A aventura antropológica. Rio de Janeiro (RJ): Zahar, 1978.

5. Da Matta R. Relativizando: uma introdução a Antropologia Social. Rio de Janeiro (RJ): Rocco; 1999.

6. Silva VG. 0 antropólogo e sua magia: trabalho de campo e texto etnográfico nas pesquisas antropológicas sobre religiões afrobrasileiras. São Paulo (SP): Ed USP; 2000.

7. Becker HS. Métodos de pesquisa em Ciências Sociais. 4. ${ }^{a}$ ed. Tradução de Marco Estevão e Renato Aguiar. São Paulo (SP): HUCITEC; 1999.

8. Ministério da Saúde (BR). Diretrizes e normas regulamentadoras de pesquisa envolvendo seres humanos. Resolução n. ${ }^{0}$ 96/96 do Conselho Nacional de Saúde. Brasília (DF); 2000.

9. Bardin L. Análise de conteúdo. Lisboa (PO): Edições 70; 1997.

10. Laville C, Dionne I. Construção do saber: manual de metodologia da pesquisa em Ciência Humanas. Tradução de Heloísa Monteiro e Francisco Settineri. Porto Alegre (RS): Artes Médicas Sul; 1999.
11. Loyola Miranda CM. Algumas questões sobre assistência de enfermagem psiquiátrica de qualidade. Cadernos IPUB 1996; 3: 77-82.

12. Loyola Miranda CM. Enfermagem e reforma psiquiátrica. Esca Anna Nery Rev Enferm 1997 dez; 1(2): 114-41.

13. Loyola Miranda CM. 0 serviço de enfermagem no IPUB: 1994. Cadernos IPUB 1998; 199-204. Número temático dos 60 anos do IPUB.

14. Loyola Miranda CM et al. Uma análise crítica quanto às condições que envolvem a indicação da terapia por eletrochoque em clientes psiquiátricos. J Bras Psiquiatr 1998 fev; 47(2): 67-72.

15. Loyola Miranda CM. Internação psiquiátrica e reabilitação psicossocial. . J Bras Psiquiatr 1998 set; 47: 437-39.

16. Loyola Miranda CM, Rocha RM, Sobral VSS. 0 ensino, a pesquisa e a assistência de enfermagem psiquiátrica. Rev Enferm UERJ 1999 jul/dez; 7(2): 193-97.

17. Loyola Miranda CM. 0 cuidado como inclusão do sujeito. Esc Anna Nery Rev Enferm 2000 abr; 4(1/3): 129-37.

18. Loyola Miranda CM, Rocha RM. Compreensão e crítica para uma clínica de enfermagem psiquiátrica [Apresentação]. Cadernos IPUB 2000; 6(19): 7-10.

19. Loyola Miranda CM, Figueiredo AC, Vieira MA. Compreensão e crítica para uma clínica de enfermagem psiquiátrica. Cuidando de quem cuida: uma experiência de supervisão em enfermagem. Cadernos IPUB 2000; 6(19): 11-14.

20. Saraceno B. Liber tando identidades: da reabilitação psicossocial à cidadania possível. Tradução de Lucia Helena Zanetta, Maria do Carmo Zanetta e Willian Valentini. Rio de Janeiro (RJ): Té Corá; 1999. 
21. Collière MF. Promover a vida - da prática de mulheres de virtude aos cuidados de enfermagem. Tradução de Maria Leonor Braga Abecasis. Lisboa (PO): Lidel; 1999.

22. Corbisier C. A reforma psiquiátrica: avanços e limites de uma experiência In: Amarante P, organizador. Ensaios-subjetividade, saúde mental e sociedade. Rio de Janeiro (RJ): FIOCRUZ; 2000.

23. Lopes MJM. Quando a voz e a palavra são atos terapêuticos: a interação individual e coletiva são palavras quotidianas do trabalho de enfermagem. In: Waldow VR, Lopes MJM, Meyer DE, organizadoras. Maneiras de cuidar, maneiras de ensinar: a enfermagem entre a escola e a prática profissional. Porto Alegre (RS): Artes Médicas 1995.

24. Silva AL. 0 cuidado no encontro de quem cuidado e de quem é cuidado. In: Meyer DE, Waldow VR, Lopes MJM, organizadoras. Marcas da diversidade: saberes e fazeres da enfermagem contemporânea. Porto Alegre (RS): Artes Médicas; 1998.

25. Goldberg J. Clínica da psicose. Rio de Janeiro: Te Corá: Instituto Franco Basaglia, 1994.

26. Boff L. Saber cuidar: ética do humano - compaixão pela terra. Petrópolis (RJ): Vozes; 1999.

\section{Notas}

a Esta pesquisa é um recorte da tese de doutorado intitulada "0 familiar e o exótico no cuidado de enfermagem em unidade de internação psiquiátrica: uma transição do asilar para a reabilitação psicossocial:", defendida no Programa de Pós-graduação Stricto Sensu da Escola de Enfermagem Anna Nery/UFRJ, em março de 2002.

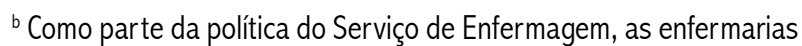
1 e 2 do IPUB, que eram divididas em enfermaria masculina e enfermaria feminina, foram transformadas em enfermarias que usavam o critério clínico sobre a condição de saúde apresentadas pelos pacientes, em crise aguda e em convalescença respectivamente, nas quais ficavam pacientes de ambos os sexos. Na enfermaria de convalescentes realizou-se este estudo. Atualmente, houve uma reversão desse entendimento e as enfermarias novamente adotaram o critério de sexos separados, um deles para cada enfermaria.

\section{Sobre as Autoras}

\section{Edna Gurgel Casanova}

Professora Titular de Enfermagem Psiquiátrica no Curso de Graduação em Enfermagem da Universidade Severino Sombra. Vassouras - RJ. Doutora em Enfermagem pela Escola de Enfermagem Anna Nery (EEAN)/UFRJ

\section{Isaura Setenta Porto}

Professora Adjunta e Doutora-pesquisadora do Núcleo de Pesquisa em Enfermagem Hospitalar do Departamento de Enfermagem MédicoCirúrgica da EEAN/UFRJ. Pesquisadora do CNPq.

\section{Nébia Maria Almeida de Figueiredo}

Professora Titular do Departamento de Enfermagem Fundamental, Coordenadora da Fábrica de Cuidados e Coordenadora do Mestrado em Enfermagem da Escola de Enfermagem Alfredo Pinto/UNIRIO. Doutora em Enfermagem pela EEAN/UFRJ. 